\title{
Bronchiectasis in COPD patients: more than a comorbidity?
}

\author{
This article was published in the following Dove Press journal: \\ International Journal of COPD \\ II May 2017 \\ Number of times this article has been viewed
}

\author{
Miguel Angel Martinez- \\ Garcia ${ }^{1,2}$ \\ Marc Miravitlles 2,3 \\ 'Pneumology Department, Hospital \\ Universitario y Politécnico La Fe, \\ Valencia, Spain; ${ }^{2}$ CIBER de \\ Enfermedades Respiratorias (CIBERES), \\ Spain; ${ }^{3}$ Pneumology Department, \\ Hospital Universitari Vall d'Hebron, \\ Barcelona, Spain
}

\begin{abstract}
Computed tomography scan images have been used to identify different radiological COPD phenotypes based on the presence and severity of emphysema, bronchial wall thickening, and bronchiectasis. Bronchiectasis is defined as an abnormal dilation of the bronchi, usually as a result of chronic airway inflammation and/or infection. The prevalence of bronchiectasis in patients with COPD is high, especially in advanced stages. The identification of bronchiectasis in COPD has been defined as a different clinical COPD phenotype with greater symptomatic severity, more frequent chronic bronchial infection and exacerbations, and poor prognosis. A causal association has not yet been proven, but it is biologically plausible that COPD, and particularly the infective and exacerbator COPD phenotypes, could be the cause of bronchiectasis without any other known etiology, beyond any mere association or comorbidity. The study of the relationship between COPD and bronchiectasis could have important clinical implications, since both diseases have different and complementary therapeutic approaches. Longitudinal studies are needed to investigate the development of bronchiectasis in COPD, and clinical trials with treatments aimed at reducing bacterial loads should be conducted to investigate their impact on the reduction of exacerbations and improvements in the long-term evolution of the disease.
\end{abstract}

Keywords: COPD, bronchiectasis, infection, exacerbations, natural history, clinical phenotype

\section{Introduction}

Patients with COPD may present with different clinical characteristics, prognoses, and response to treatment. ${ }^{1}$ This has resulted in increased efforts to identify subgroups of patients that share similar characteristics - the so-called clinical phenotypes - in order to provide more individualized and effective therapy. ${ }^{2,3}$ Some studies have attempted to determine these phenotypes by investigating the morphological findings observed in lung computed tomography (CT) scans. ${ }^{4}$ In this respect, the presence of pulmonary emphysema, ${ }^{4}$ bronchial wall thickening, ${ }^{5}$ and bronchiectasis ${ }^{6}$ have been proposed as three of the main morphological findings likely to provide relevant information about different phenotypes of COPD.,7

Bronchiectasis is defined as irreversible and generally progressive dilation of the airways. Some 30 years ago, $\mathrm{Cole}^{8}$ proposed a pathogenic vicious circle originating from chronic bronchial infection caused by potentially pathogenic microorganisms (PPMs) and the consequent chronic inflammation which results in remodeling of the airways and damage to local defense mechanisms, which in turn facilitate the persistence of PPMs in the bronchial tree despite the administration of treatment. Chronic bronchial infection is also frequently found in patients with COPD and would provide a link between the two diseases. ${ }^{9}$ 
The relationship between bronchiectasis and COPD has generated several questions. Is there any real increased prevalence of bronchiectasis in patients with COPD? Does the presence of bronchiectasis have an impact on the clinical characteristics, prognosis, or response to treatment in COPD, to the extent that it can be considered a distinct clinical phenotype? Should bronchiectasis in patients with COPD be seen as merely a comorbidity, or as a consequence of the disease's natural history? Is there a causal relationship between COPD and bronchiectasis? If this is the case, what are the pathophysiological mechanisms responsible for this relationship? And, finally, what is the role of chronic bronchial infection and exacerbations in this relationship?

\section{COPD and bronchiectasis: under- and misdiagnosis}

COPD and bronchiectasis are very prevalent in the general population. In Spain up to $10 \%$ of the adult population has $\mathrm{COPD}^{10}$ and $1.5 \%$ of men older than 65 years have bronchiectasis; ${ }^{11}$ therefore, they may both coexist. Although the diagnosis of COPD is based on physiology and that of bronchiectasis on morphology, both diseases may result in similar lung function abnormalities and non-specific respiratory symptoms. As a consequence, there is a strong possibility of misdiagnosis in favor of COPD, because spirometry is more widely available than CT scans and physicians usually think primarily about COPD when confronted with a smoker with cough, sputum production, and airflow obstruction. ${ }^{12}$ In this respect, O'Brien et $\mathrm{al}^{13}$ observed that approximately one third of patients referred from primary care with a COPD diagnosis had bronchiectasis demonstrated by CT scan, even with normal spirometric values. Furthermore, in COPD patients with pulmonary hypertension, the diagnostic criterion for bronchiectasis (based on the demonstration of a bronchial lumen diameter greater than the diameter of the adjacent vessel) may be misleading. ${ }^{14}$

\section{Prevalence of bronchiectasis in COPD}

The prevalence of bronchiectasis in patients with COPD has been analyzed in several studies, with conflicting results ranging from $4 \%$ to $72 \%$ (Table 1 ). ${ }^{4,15-28}$ The methodologies used in these studies were very diverse. They differed in the characteristics of the patients included (different severity, non-consecutive inclusion, or inclusion during exacerbations), the use of different CT diagnostic criteria for bronchiectasis, or the study's objective (related or unrelated to bronchiectasis analysis). These differences may partly explain the disparities found in the reported prevalence.

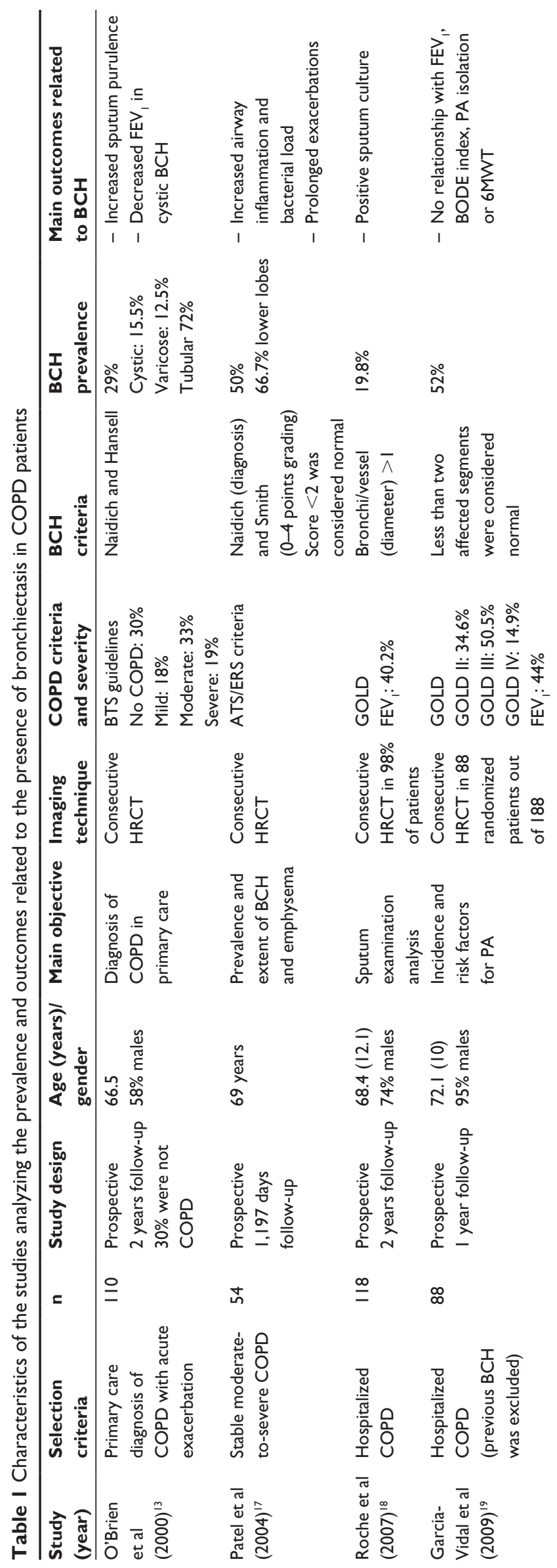




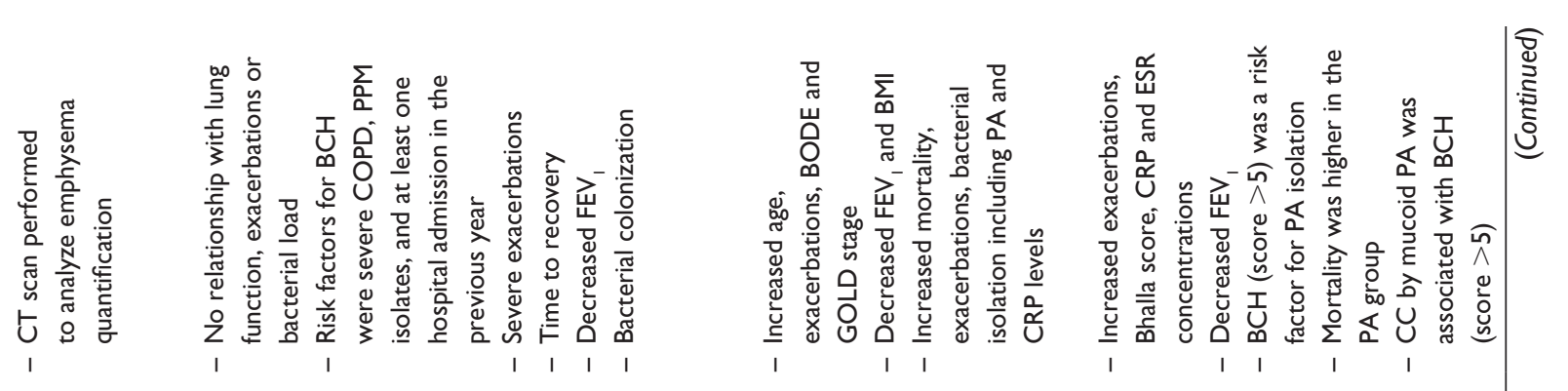

วั ڤㅇํ

ํำ

$\ddot{\equiv} \stackrel{\equiv}{\equiv}$

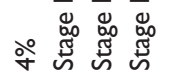

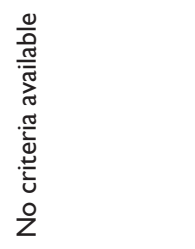

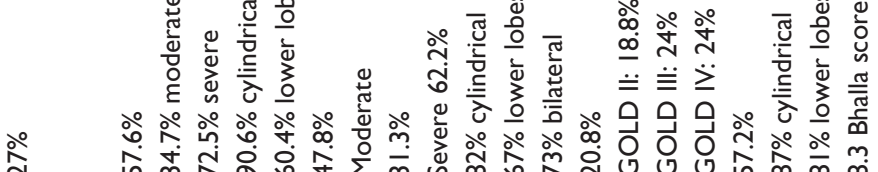

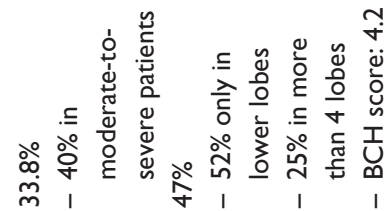

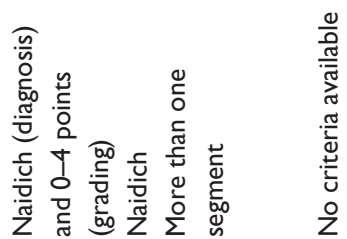

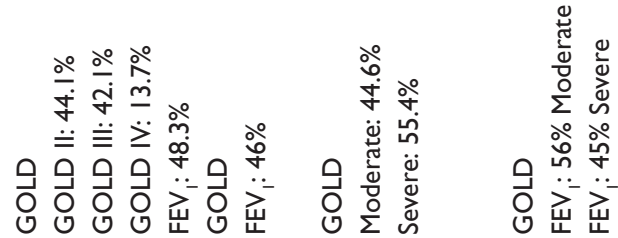

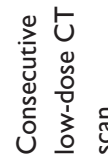

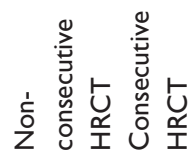

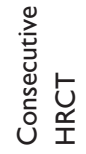

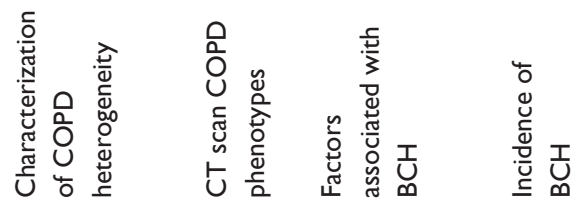

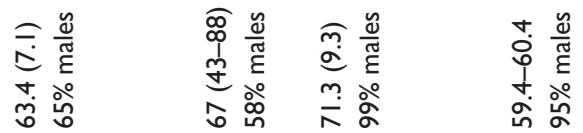

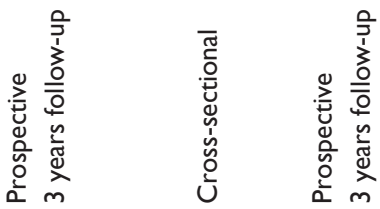

$\frac{\mathrm{i}}{\mathrm{i}}$

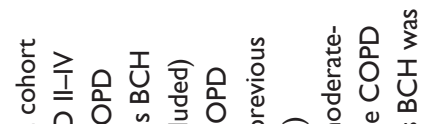

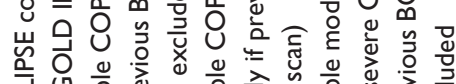

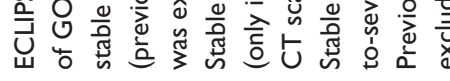

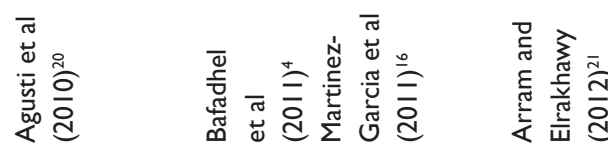

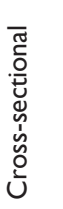

a

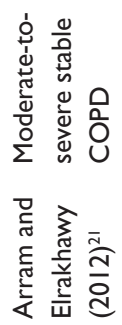

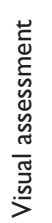

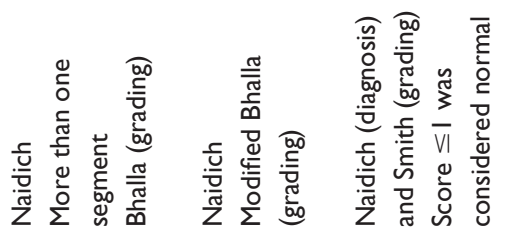

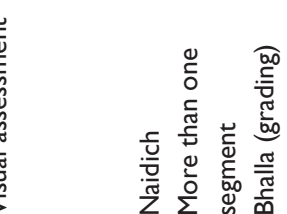

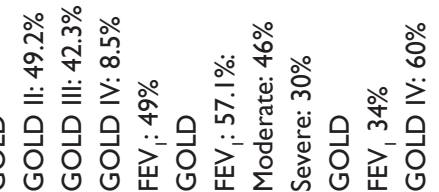

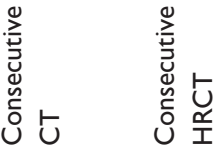

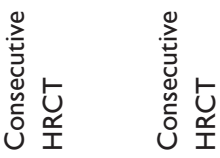

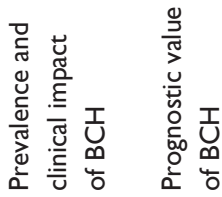

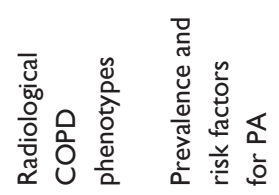

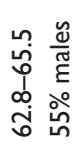

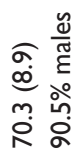

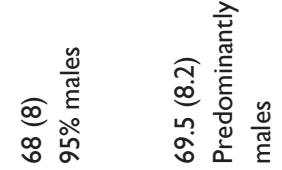

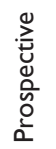

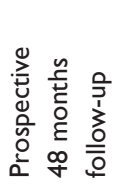

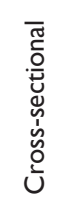

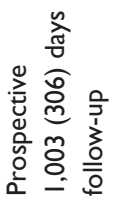

$\stackrel{\text { ก }}{\text { m }}$

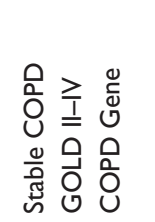

$\overline{\mathrm{i}}$

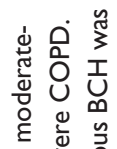

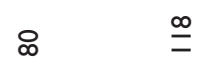




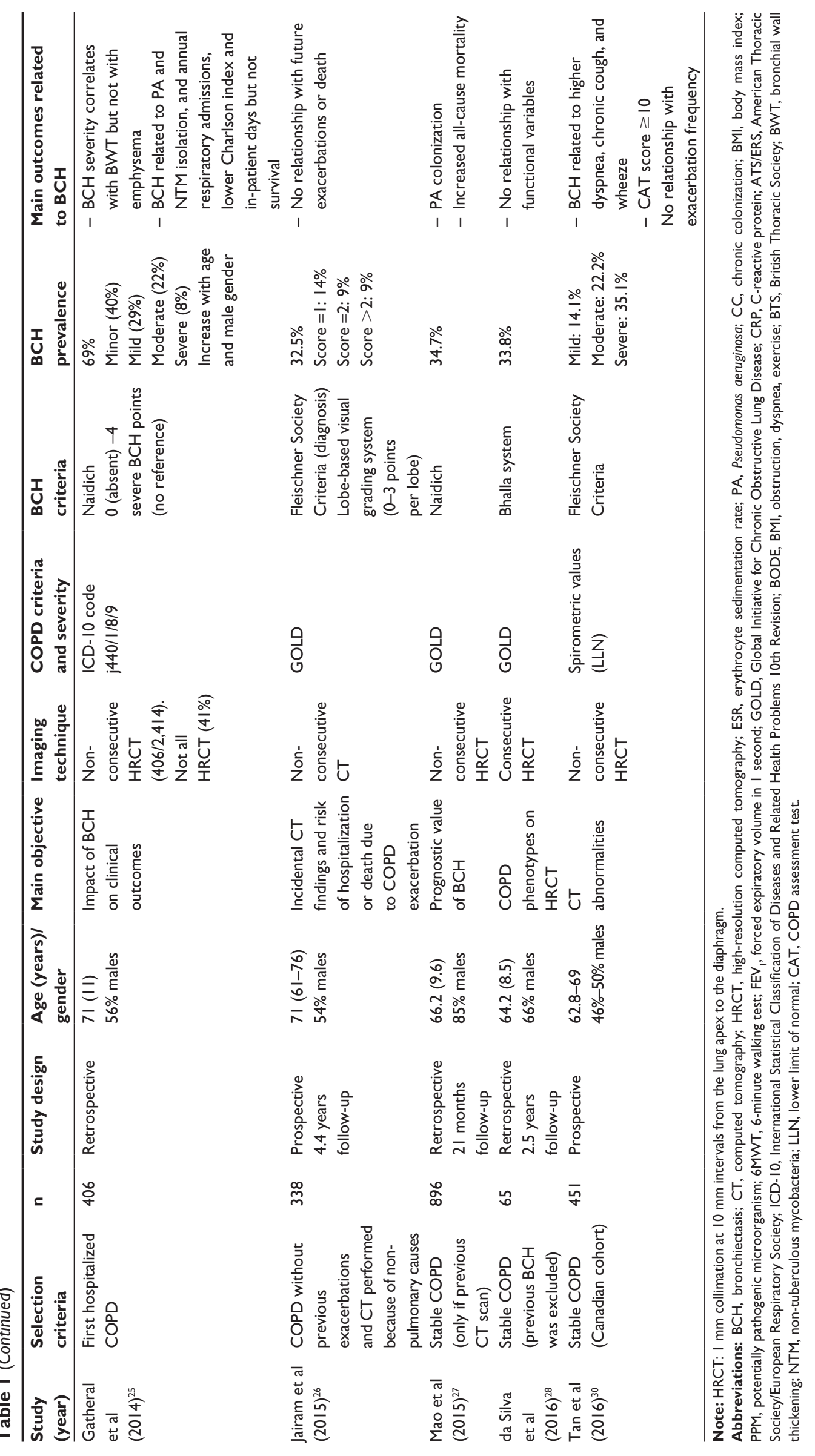


Table 2 Characteristics of patients with COPD and bronchiectasis compared with COPD patients without bronchiectasis

General characteristics

- Older patients

- Higher frequency of males

- Heavier smokers

Clinical features

- Increased daily sputum production

- Increased number of exacerbations

Lung function parameters

- More severe airflow obstruction (measured by $\mathrm{FEV}_{1} / \mathrm{FVC}$ and $\mathrm{FEV}_{1} \%$ predicted)

Inflammatory markers

- Higher levels of peripheral CRP

- Lower concentration of albumin

Microbiological profile

- Increased prevalence of PPM colonization

- Increased prevalence of Pseudomonas aeruginosa colonization

Prognostic features

- Doubled risk of all-cause mortality

Notes: Based on two meta-analyses by $\mathrm{Ni}$ et $\mathrm{al}^{3{ }^{3}}$ and $\mathrm{Du}$ et $\mathrm{al} .^{32}$ Variables in bold are those with the highest odds ratios in the meta-analysis.

Abbreviations: CRP, C-reactive protein; $\mathrm{FEV}_{1} / \mathrm{FVC}$, forced expiratory volume in I second/forced vital capacity; PPM, potentially pathogenic microorganism.

Moreover, most of these studies excluded patients with previously known bronchiectasis and those with bronchiectasis in only one pulmonary segment, as this circumstance can be found in a significant percentage of elderly people in the general population, or in smokers with no airway obstruction..$^{29}$ Recently, Tan et a ${ }^{30}$ found that $19.9 \%$ of healthy individuals had bronchiectasis compared with $35.1 \%$ of severe COPD patients of the same age. This means that the real prevalence of bronchiectasis in COPD patients might be overestimated, and other $\mathrm{CT}$ characteristics such as bronchial wall thickening should be used to differentiate real bronchiectasis in COPD from bronchiectasis associated with aging. ${ }^{14}$

In patients with COPD the characteristics found to be associated with a higher prevalence of bronchiectasis include advanced age, ${ }^{22}$ male gender, ${ }^{25}$ and a history of previous exacerbations. ${ }^{13,15,18,19,25}$ The bronchiectasis observed in patients with COPD is usually cylindrical (72\%-90\%), predominantly in both pulmonary bases $(52 \%-81 \%)$, bilateral (52\%-67\%), and with moderate scores in radiological analyses of severity. ${ }^{13-17,21,23}$ Interestingly, one consistent finding is the relationship between the increased severity of COPD and the higher prevalence of bronchiectasis. ${ }^{16,20-22,24,25}$

\section{Impact of bronchiectasis on COPD}

The impact of bronchiectasis on the natural history of COPD has been analyzed in two recent meta-analyses ${ }^{31,32}$ and can be summarized as follows (Table 2).

\section{Clinical aspects}

The presence of bronchiectasis in COPD has been associated with a lower body mass index, ${ }^{22}$ older age, ${ }^{22,25}$ a greater production and purulence of sputum, ${ }^{17}$ a greater number of comorbidities, ${ }^{25}$ and a higher body mass index, airflow obstruction, dyspnea, and exercise index. ${ }^{22}$ However, the most widely recognized association is a greater frequency and severity of exacerbations, identified for the first time by Patel et al, ${ }^{17}$ and confirmed in subsequent studies. ${ }^{16,22-26}$

\section{Microbiological aspects}

The variable most consistently associated with the presence of bronchiectasis in patients with COPD is chronic bronchial infection by PPMs (odds ratio [OR] between 3.76-7.33), particularly Pseudomonas aeruginosa (OR between 3.5-4.75), along with the existence of a greater bacterial load. ${ }^{17}$

\section{Functional aspects}

There is also significant agreement that the presence of bronchiectasis is associated with more severe bronchial obstruction. ${ }^{13,15,21-23}$

\section{Inflammatory aspects}

The presence of bronchiectasis has been associated with an increase in both local and systemic inflammation. ${ }^{17,23,24}$ Patel et al ${ }^{17}$ observed that patients with bronchiectasis presented an increase in the concentrations of IL- 8 and IL- 6 in sputum as a result of the greater bacterial load. Similarly, two studies observed an increase in C-reactive protein and erythrocyte sedimentation rate in peripheral blood. ${ }^{23,24}$

\section{Prognostic aspects}

Only a few studies have analyzed the relationship between the presence of bronchiectasis and poor outcomes in patients with COPD. A prospective study on 201 consecutive patients with stable COPD followed-up for 48 months concluded that the presence of bronchiectasis was associated with greater mortality (OR: $2.45 ; P=0.02$ ), independent of age, the presence of comorbidities, or the severity of airway obstruction; ${ }^{23}$ these results were confirmed by Mao et al. ${ }^{27}$ In contrast, another two studies - one performed on 406 COPD patients during a severe exacerbation ${ }^{25}$ and another on 338 patients with no previous exacerbations ${ }^{26}$ - did not find any association between the presence of bronchiectasis and greater mortality. However, the meta-analysis by Du et a ${ }^{32}$ concluded that the mortality risk in COPD is significantly increased in the presence of bronchiectasis with an OR of 1.96 (95\% confidence interval $=1.04-3.70$ ). 


\section{Searching for causality: is this possible?}

A further advance in our understanding of the interaction between COPD and bronchiectasis would be to know whether bronchiectasis in COPD patients develops as a result of COPD or its determining factors, such as smoking, presence of chronic bronchial infection, and exacerbations.

Even though some etiological classifications of bronchiectasis include COPD as one of its causes, so far no longitudinal study has demonstrated any causal relationship, although Bradford Hill's classic etiologic criteria ${ }^{33}$ could provide the basis for an argument in favor of this possibility.

\section{Strength of association}

Two recent meta-analyses concluded that the presence of PPMs (OR: 7.33 and 3.76, respectively), colonization by P. aeruginosa (OR: 3.50 and 4.75 , respectively), and a greater number of exacerbations (OR: 1.97 and 1.54, respectively) ) $^{31,32}$ were the variables most strongly associated with the presence of bronchiectasis in COPD. Although it is still unknown whether chronic bronchial infection and frequent exacerbations occur before or after the development of bronchiectasis in patients with COPD, the results of these meta-analyses support the pathophysiological hypothesis that development of bronchiectasis in COPD is associated with chronic bronchial infection and frequent exacerbations.

\section{Time sequence}

This would be based on the observation of "de novo" bronchiectasis in COPD patients in whom it was not previously present. Figure 1 shows a patient who, in 2007, presented with severe COPD (forced expiratory volume in 1 second $\left[\mathrm{FEV}_{1}\right]$ : $49 \%$ predicted), chronic bronchitis, and frequent exacerbations but had no bronchiectasis detected by high-resolution computed tomography (HRCT) scan at that time. The same patient participated in a new study 8 years later, when his $\mathrm{FEV}_{1}$ was $29 \%$ predicted, revealing bibasal cylindrical bronchiectasis. In spite of an exhaustive etiological study, it was impossible to identify any cause for bronchiectasis other than COPD itself. Longitudinal studies involving repeated HRCT are required to confirm a time sequence that would support a causal relationship between the two diseases.

\section{Dose-response effect}

The dose-response effect could be applied to the higher prevalence of bronchiectasis observed in patients with a greater severity of COPD. . $^{16,20-22,24,25}$

\section{Consistency}

Consistency refers to the percentage of studies that reach the same conclusions. In this respect, most studies have observed not only a high prevalence of bronchiectasis, but also a similar pattern, comprising cylindrical, bilateral, and bibasal bronchiectasis. ${ }^{15-17,23}$ Furthermore, bronchiectasis seems to be found more frequently in older patients ${ }^{22}$ and heavier smokers, which would concur with the hypothesis that bronchiectasis occurs as a consequence of years of bronchial inflammation or infection.

\section{Biological plausibility}

Subjects with COPD present different forms of impaired immunity that facilitate the survival and proliferation of
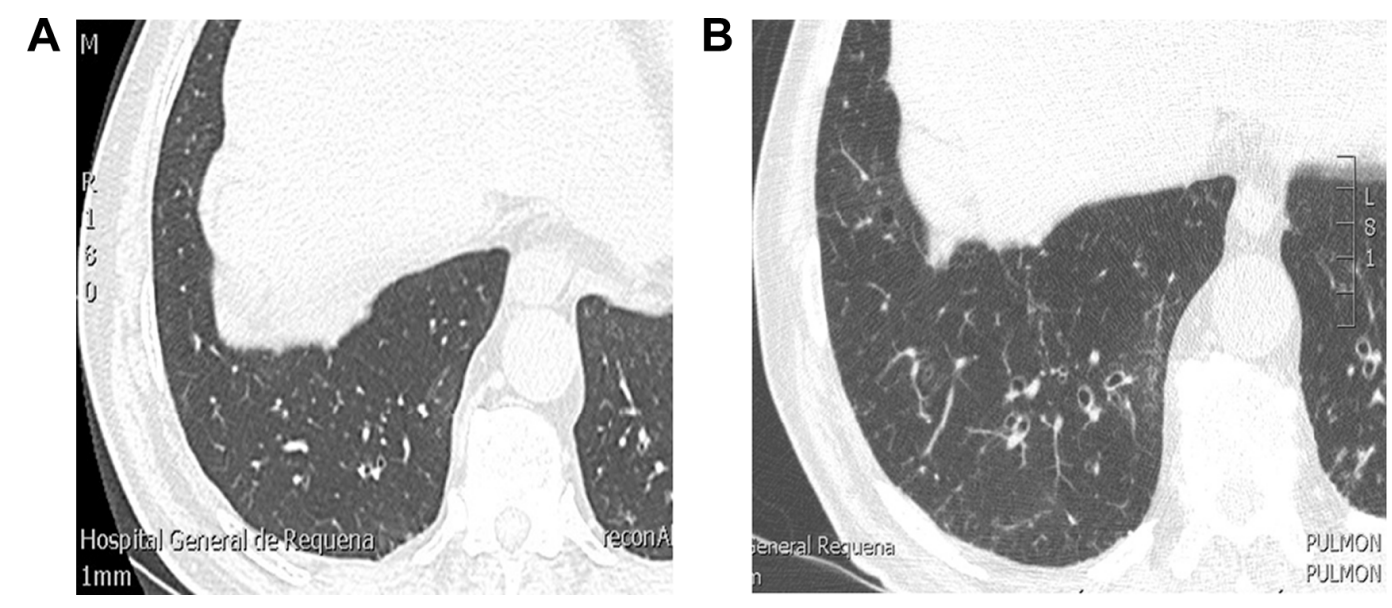

Figure I Development of bronchiectasis in a patient with severe COPD.

Notes: (A) HRCT scan without bronchiectasis in 2007 and (B) HRCT scan from the same patient and slide in 2015.

Abbreviation: HRCT, high-resolution computed tomography. 


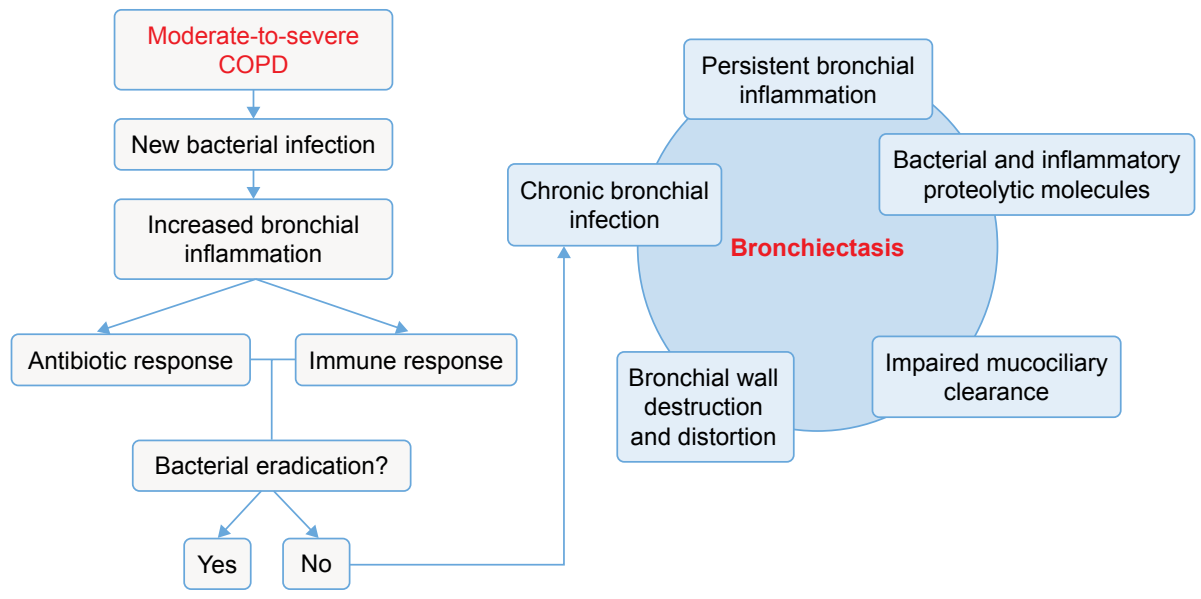

Fall \& rise hypothesis

Cole's vicious circle

Figure 2 Pathophysiological hypothesis of the development of bronchiectasis in patients with COPD.

Notes: Reproduced from Martinez-Garcia MA, Maiz L, De la Rosa D. The overlap with bronchiectasis. In: Anzueto A, Heijdra Y, Hurst JR, editors. Controversies in COPD. European Respiratory Society; 2015: 105. ${ }^{33}$ With permission from European Respiratory Society. (C) 2015, European Respiratory Society.

PPMs in the lower airways. In fact, microbiological cultures of sputum are positive for PPMs in about $40 \%-70 \%$ of patients with stable COPD. ${ }^{9,34-36}$ This chronic bronchial infection unleashes a persistent bronchial inflammation and these two together progressively damage the bronchial wall through the release of bacterial and inflammatory proteolytic products, leading to the formation of bronchiectasis, in accordance with the classic postulates of Cole, ${ }^{8}$ described previously. The reduced activity of many antimicrobials as a result of the chronic bronchial infection and the difficult diffusion to the bronchial secretions resulting from the presence of bronchiectasis, makes it much more difficult to eradicate the PPMs, and so the process becomes chronic, thereby increasing the frequency and severity of the exacerbations in a patient with COPD. This sequence of events is illustrated in Figure 2.

\section{Analogy}

This refers to the existence of similar examples that would explain the relationship that needs to be demonstrated. The origin of bronchiectasis in patients with cystic fibrosis could be a valid example in this respect. ${ }^{37}$

\section{Experimental evidence}

There is no evidence to date of any delay to, or non-appearance of bronchiectasis in patients with COPD as a result of prophylactic treatment for exacerbations or long-term anti-inflammatory or antibiotic treatment, although this would undoubtedly be one of the main objectives of future studies.

\section{Bronchiectasis-COPD overlap: comorbidity or a distinct clinical phenotype?}

COPD can exist without bronchiectasis and bronchiectasis is often not present alongside chronic airflow obstruction; however, when bronchiectasis of unknown etiology is demonstrated in a patient with COPD it is difficult to accept that it is merely a comorbidity that appeared by chance. Tobacco smoking is the main etiological factor for COPD, and it also impairs lung defense mechanisms and facilitates chronic and acute infection. The role of infection in the cascade of events that accelerate the progression of COPD in smokers, and how it can be a key player in the development of bronchiectasis, has already been addressed. It is therefore reasonable to assume that in some patients the two diseases, COPD and bronchiectasis, may be clinical manifestations of the same process, justifying the overlapping term or clinical phenotype COPDbronchiectasis. ${ }^{38-40}$ It is interesting to observe that a significant proportion of patients with bronchiectasis included in clinical trials were also smokers with chronic airflow obstruction. ${ }^{41}$ This highlights the strong relationship between these two entities, but is it a case of bronchiectasis with airflow obstruction, or COPD with bronchiectasis? Hurst et $\mathrm{a}^{40}$ highlighted the importance of differentiating between patients with bronchiectasis who present with not fully reversible airflow obstruction and COPD patients presenting the anatomical abnormalities of bronchiectasis. This second case would fulfil the criteria of a phenotype of the COPD disease spectrum. ${ }^{40}$

The diagnosis of the COPD-bronchiectasis phenotype will have clinical implications for more frequent chronic 


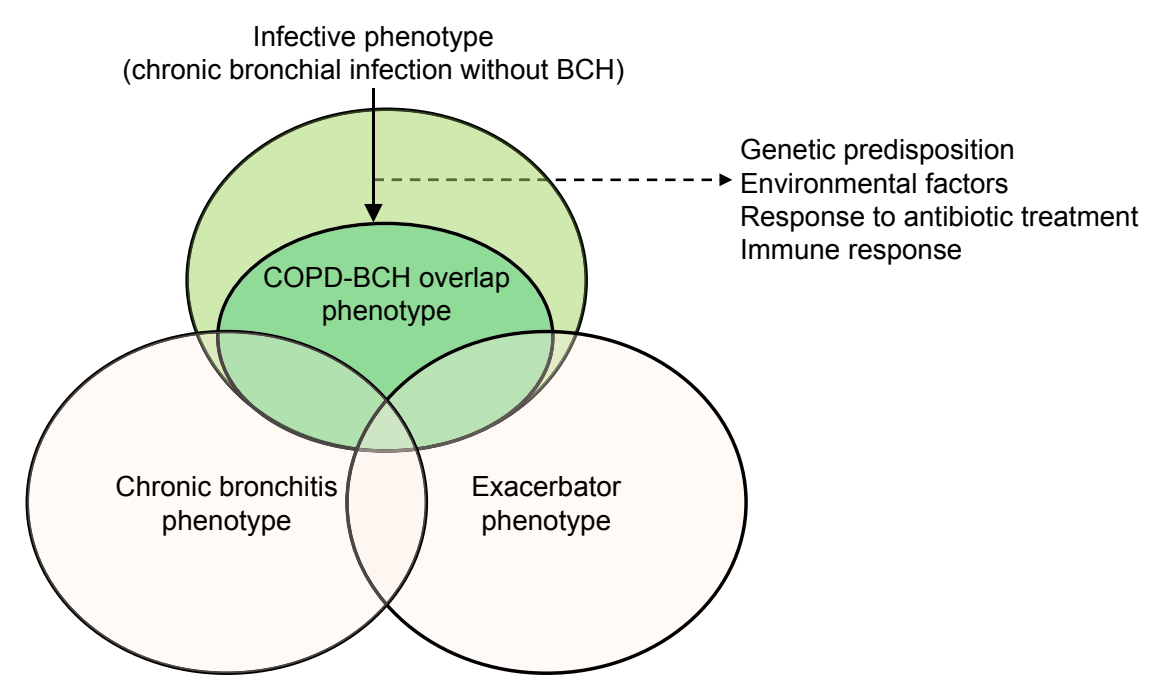

Figure 3 Relationship between COPD-bronchiectasis overlap phenotype and infective and chronic bronchitis and exacerbator phenotypes. Abbreviation: $\mathrm{BCH}$, bronchiectasis.

bronchial infection, impairment in respiratory symptoms (cough and sputum), more frequent and severe exacerbations, and impaired health-related quality of life. These signs and symptoms are very similar to those of the COPD-infective phenotype and there must be a huge overlap between them. ${ }^{3,42}$ It can be speculated that the COPD-bronchiectasis phenotype may be a sub-phenotype or an evolution of the infective phenotype of COPD (Figure 3), characterized by chronic bronchial infection by PPMs and frequent bacterial exacerbations. ${ }^{42}$ Some patients with COPD and infective phenotype may have developed bronchiectasis, but others may be in the initial stages of the disease and would be susceptible to therapeutic strategies aimed at suppressing bacterial growth and avoiding bacterial persistence, in order to prevent the development of bronchiectasis. Unfortunately, no longitudinal studies are yet available to confirm this sequence of events.

The COPD-bronchiectasis phenotype would also overlap with the chronic bronchitis and frequent exacerbator phenotypes $^{3}$ (Figure 3). In contrast to the previously mentioned phenotypes, the COPD-bronchiectasis phenotype is stable and can be objectively diagnosed via imaging. ${ }^{43}$ Some national guidelines have included the COPD-bronchiectasis phenotype as an important clinical phenotype that need to be considered in the treatment of COPD. ${ }^{44}$

\section{Bronchiectasis in COPD: therapeutic consequences}

Although the presence of bronchiectasis in patients with COPD is usually associated with chronic bronchial infection and more frequent exacerbations, mostly of a bacterial etiology, ${ }^{25,31,32}$ this infective component is not adequately covered by the usual treatment for COPD based on inhaled therapy with bronchodilators, with or without inhaled corticosteroids (ICS). Some recent studies have demonstrated that even patients on triple therapy may suffer from frequent exacerbations ${ }^{45}$ One of the reasons would be the lack of appropriate treatment for the infective component of the disease. An HRCT scan of the thorax must be performed in patients with COPD and frequent exacerbations, and when bronchiectasis is identified, they must receive treatment for both COPD and bronchiectasis, in the latter case mainly aimed at controlling chronic and acute infection.

There have not been any trials of therapies for COPD complicated by bronchiectasis. In most pharmacologic clinical trials on COPD the presence of significant bronchiectasis is an exclusion criterion; therefore, no recommendations can be formulated on the basis of solid evidence, although special attention must be paid to anti-inflammatory and antibiotic therapies.

The efficacy of ICS in COPD is controversial, particularly in patients with frequent bacterial exacerbations and/or low concentrations of bronchial or blood eosinophils, as may be the case in patients with associated bronchiectasis. Furthermore, the use of ICS may be associated with an increase in the bronchial bacterial load in patients with COPD and chronic bronchial infection; ${ }^{46}$ in fact, ICS are not indicated as maintenance treatment in bronchiectasis, ${ }^{47}$ and the last update of the GOLD strategy indicates that in the case of associated bronchiectasis, ICS may not be indicated in patients with bacterial colonization or recurrent lower respiratory tract infections. ${ }^{48}$ Therefore, unless patients present with high blood eosinophil levels and/or clinical signs of bronchial hyper-responsiveness, ${ }^{49}$ ICS should not be used, 
or only used at the lowest possible dosage. One alternative may be the use of macrolides or roflumilast, which is effective in neutrophilic inflammation and in patients with chronic cough and sputum production, ${ }^{50}$ both characteristics of bronchiectasis in COPD.

There have been therapeutic trials on bronchiectasis that include adult smokers with airflow obstruction that is not fully reversible and similar to COPD. ${ }^{41}$ From these trials we can speculate that the use of long-term macrolides or inhaled antibiotics could be beneficial in reducing exacerbations in these patients. ${ }^{50}$ Other strategies such as physiotherapy must also be considered. ${ }^{47}$

\section{What do we need from future studies on this topic?}

To analyze the true prevalence of bronchiectasis in COPD patients, large studies of consecutive stable COPD patients from international registries should be performed. Bronchiectasis diagnosis should be made by means of HRCT scans interpreted with uniform radiological criteria, taking into account the existence of bronchial dilations mimicking bronchiectasis in the elderly.

The causal relationship between COPD and bronchiectasis requires longitudinal studies to be adequately assessed. These studies should include evaluation of the lungs by repeated HRCT scans to verify the development of "de novo" bronchiectasis in subjects with COPD, and they should investigate the related factors that predispose to this association. Longitudinal studies should also confirm the prognostic impact of bronchiectasis on outcomes such as exacerbations, hospitalizations, and mortality in COPD.

Another interesting aspect for future research is the study of specific biomarkers linking COPD and bronchiectasis, especially those related to neutrophilic inflammation, COPD severity, exacerbations, bronchial wall thickening, or increased susceptibility to chronic bronchial infection. ${ }^{51}$ The composition and relevance of the lung microbiome and its changes with the evolution of the disease, or with treatment, provide another area for future research. ${ }^{52}$

Finally, therapeutic trials should be conducted on patients with COPD and bronchiectasis to investigate the efficacy and safety of specific treatments such as mucolytics, phosphodiesterase IV inhibitors, long-term macrolides, and inhaled antibiotics, particularly in more severe patients with a high risk of exacerbations and chronic bronchial infection.

\section{Conclusion}

The prevalence of bronchiectasis in patients with COPD is high. Some of the etiological factors for bronchiectasis are present in patients with COPD, and may be responsible for the development of bronchiectasis in susceptible individuals. It is not clear why some patients with COPD develop bronchiectasis and others do not, but the presence of a chronic bronchitis phenotype may determine an increased risk of chronic bronchial infection and recurrent infective exacerbations, which perpetuate the vicious circle of infection, inflammation, and tissue destruction. The presence of bronchiectasis in COPD is associated with more frequent and severe exacerbations, impaired quality of life, and possibly reduced survival. Longitudinal studies are needed to investigate the development of bronchiectasis in COPD, and clinical trials with treatments aimed at reducing bacterial loads should be conducted to investigate their impact on the reduction of exacerbations and improvements in the long-term evolution of the disease.

\section{Disclosure}

The authors report no conflicts of interest in this work.

\section{References}

1. Decramer M, Janssens W, Miravitlles M. Chronic obstructive pulmonary disease. Lancet. 2012;379(9823):1341-1351.

2. Han MK, Agusti A, Calverley PM, et al. Chronic obstructive pulmonary disease phenotypes: the future of COPD. Am J Respir Crit Care Med. 2010;182(5):598-604.

3. Miravitlles M, Calle M, Soler-Cataluña JJ. Clinical phenotypes of COPD: identification, definition and implications for guidelines. Arch Bronconeumol. 2012;48(3):86-98.

4. Bafadhel M, Umar I, Gupta S, et al. The role of CT scanning in multidimensional phenotyping of COPD. Chest. 2011;140(3):634-642.

5. Mair G, Maclay J, Miller JJ, et al. Airway dimensions in COPD: relationship with clinical variables. Respir Med. 2010;104(11):1683-1690.

6. Martinez-Garcia MÁ, Selma MJ, Navarro C, Muñoz-Reina A. Bronchiectasis phenotype in COPD patients. Clin Pulm Med. 2015;22(3):123-127.

7. Lynch DA, Austin JH, Hogg JC, et al. CT-definable subtypes of chronic obstructive pulmonary disease: a statement of the Fleischner Society. Radiology. 2015;277(1):192-205.

8. Cole PJ. Inflammation: a two edged-sword-the model of bronchiectasis. Eur J Respir Dis Suppl. 1986;147:6-15.

9. Sethi S, Murphy TF. Infection in the pathogenesis and course of chronic obstructive pulmonary disease. N Engl J Med. 2008;359(22): 2355-2365.

10. Miravitlles M, Soriano JB, García-Río F, et al. Prevalence of COPD in Spain: impact of undiagnosed COPD on quality of life and daily life activities. Thorax. 2009;64(10):863-868.

11. Monteagudo M, Rodríguez-Blanco T, Barrecheguren M, Simonet P, Miravitlles M. Prevalence and incidence of bronchiectasis in Catalonia, Spain: A population-based study. Respir Med. 2016;121:26-31.

12. Miravitlles M, de la Roza C, Naberan K, et al. Attitudes towards the diagnosis of chronic obstructive pulmonary disease in primary care. Arch Bronconeumol. 2006;42(1):3-8.

13. O'Brien CO, Guest PJ, Hill SL, Stockley RA. Physiological and radiological characterisation of patients diagnosed with chronic obstructive pulmonary disease in primary care. Thorax. 2000;55(8):635-642.

14. Diaz AA, Young TP, Maselli DJ, et al. Quantitative CT measures of bronchiectasis in smokers. Chest. Epub 2016 Nov 24.

15. Gallego M, Pomares X, Espasa M, et al. Pseudomonas aeruginosa isolates in severe chronic obstructive pulmonary disease: characterization and risk factors. BMC Pulm Med. 2014;14:103. 
16. Martínez-García MÁ, Soler-Cataluña JJ, Donat Sanz Y, et al. Factors associated with bronchiectasis in patients with COPD. Chest. 2011; 140(5):1130-1137.

17. Patel IS, Vlahos I, Wilkinson TM, et al. Bronchiectasis, exacerbations indices, and inflammation in chronic obstructive pulmonary disease. Am J Respir Crit Care Med. 2004;170(4):400-407.

18. Roche N, Kouassi B, Rabbat A, Mounedji A, Lorut C, Huchon G. Yield of sputum microbiological examination in patients hospitalized for exacerbations of chronic obstructive pulmonary disease with purulent sputum. Respiration. 2007;74(1):19-25.

19. Garcia-Vidal C, Almagro P, Romaní V, et al. Pseudomonas aeruginosa in patients hospitalised for COPD exacerbations: a prospective study. Eur Respir J. 2009;34(5):1072-1078.

20. Agusti A, Calverley PM, Celli B, et al. Characterisation of COPD heterogeneity in the ECLIPSE cohort. Respir Res. 2010;11:122.

21. Arram EO, Elrakhawy MM. Bronchiectasis in COPD patients. Egyptian Journal of Chest Diseases and Tuberculosis. 2012;61(4):307-312.

22. Steward JI, Maselli DJ, Anzueto A, et al. Clinical impact of CT radiological feature of bronchiectasis in the COPDGene cohort. Am J Respir Crit Care Med. 2012;185:A3656.

23. Martínez-García MA, de la Rosa Carrillo D, Soler-Cataluña JJ, et al. Prognostic value of bronchiectasis in patients with moderate-to-severe chronic obstructive pulmonary disease. Am J Respir Crit Care Med. 2013; 187(8):823-831.

24. Tulek B, Kivrak AS, Ozbek S, Kanat F, Suerdem M. Phenotyping of chronic obstructive pulmonary disease using the modified Bhalla scoring system for high-resolution computed tomography. Can Respir J. 2013;20(2):91-96.

25. Gatheral T, Kumar N, Sansom B, et al. COPD-related bronchiectasis; independent impact on disease course and outcomes. COPD. 2014;11(6):605-614.

26. Jairam PM, van der Graaf Y, Lammers JW, Mali WP, de Jong PA; PROVIDI Study group. Incidental findings on chest CT imaging are associated with increased COPD exacerbations and mortality. Thorax. 2015;70(8):725-731.

27. Mao B, Lu HW, Li MH, et al. The existence of bronchiectasis predicts worse prognosis in patients with COPD. Scientific Reports. 2015; 5:10961.

28. da Silva SM, Paschoal IA, De Capitani EM, Moreira MM, Palhares LC, Pereira MC. COPD phenotypes on computed tomography and its correlation with selected lung function variables in severe patients. Int $J$ Chron Obstruct Pulmon Dis. 2016;11:503-513.

29. Kwak HJ, Moon JY, Choi YW, et al. High prevalence of bronchiectasis in adults: analysis of CT findings in a health screening program. Tohoku J Exp Med. 2010;222(4):237-242.

30. Tan WC, Hague CJ, Leipsic J, et al. Findings on thoracic computed tomography scans and respiratory outcomes in persons with and without chronic obstructive pulmonary disease: a population-based cohort study. PLoS One. 2016;11(11):e0166745.

31. Ni Y, Shi G, Yu Y, Hao J, Chen T, Song H. Clinical characteristics of patients with chronic obstructive pulmonary disease with comorbid bronchiectasis: a systematic review and meta-analysis. Int J Chron Obstruct Pulmon Dis. 2015;10:1465-1475.

32. Du Q, Jin J, Liu X, Sun Y. Bronchiectasis as a comorbidity of chronic obstructive pulmonary disease: a systematic review and meta-analysis. PloS One. 2016;11(3):e0150532.

33. Hill AB. The environment and disease: association or causation? Proc $R$ Soc Med.1965;58(5):295-300.

34. Marin A, Monsó E, Garcia-Nuñez M, et al. Variability and effects of bronchial colonisation in patients with moderate COPD. Eur Respir J. 2010;35(2):295-302.
35. Wilkinson TM, Patel IS, Wilks M, Donaldson GC, Wedzicha JA. Airway bacterial load and $\mathrm{FEV}_{1}$ decline in patients with chronic obstructive pulmonary disease. Am J Respir Crit Care Med. 2003;167(8): 1090-1095.

36. Miravitlles M, Marín A, Monsó E, et al. Colour of sputum is a marker for bacterial colonisation in chronic obstructive pulmonary disease. Respir Res. 2010;11:58.

37. Peters S. Cystic fibrosis: a review of pathophysiology and current treatment recommendations. S D Med. 2014;67(4):148-151.

38. O'Donnell AE. Bronchiectasis in patients with COPD: a distinct COPD phenotype? Chest. 2013;140(5):1107-1108.

39. Stockley RA. Bronchiectasis with chronic obstructive pulmonary disease: association or a further phenotype? Am J Respir Crit Care Med. 2013;187(8):786-788.

40. Hurst JR, Elborn JS, De Soyza A; BRONCH-UK Consortium. COPDbronchiectasis overlap syndrome. Eur Respir J. 2015;45(2):310-313.

41. Barker AF, O'Donnell AE, Flume P, et al. Aztreonam for inhalation solution in patients with non-cystic fibrosis bronchiectasis (AIR-BX1 and AIR-BX2): two randomised double-blind, placebo-controlled phase 3 trials. Lancet Respir Med. 2014;2(9):738-749.

42. Matkovic Z, Miravitlles M. Chronic bronchial infection in COPD. Is there an infective phenotype? Respir Med. 2013;107(1):10-22.

43. Martinez-Garcia MA, Maiz L, De la Rosa D. The overlap with bronchiectasis. In: Anzueto A, Heijdra Y, Hurst JR, editors. Controversies in COPD. European Respiratory Society; 2015:105.

44. Koblizek V, Chlumsky J, Zindr V, et al. Chronic obstructive pulmonary disease: official diagnosis and treatment guidelines of the Czech Pneumological and Phthisiological Society; a novel phenotypic approach to COPD with patient-oriented care. Biomed Pap Med Fac Univ Palacky Olomouc Czech Repub. 2013;157(2):189-201.

45. Busch R, Han MK, Bowler RP, et al. Risk factors for COPD exacerbations in inhaled medication users: the COPDGene study bianual longitudinal follow-up prospective cohort. BMC Pulm Med. 2016;16:28.

46. Garcha DS, Thurston SJ, Patel AR, et al. Changes in prevalence and load of airway bacteria using quantitative PCR in stable and exacerbated COPD. Thorax. 2012;67(12):1075-1080.

47. Pasteur MC, Bilton D, Hill AT; British Thoracic Society Bronchiectasis non-CF Guideline Group. British Thoracic Society guideline for non-CF bronchiectasis. Thorax. 2010;65 (Suppl 1):i1-i58.

48. Vogelmeier CF, Criner GJ, Martínez FJ, et al. Global Strategy for the Diagnosis, Management, and Prevention of Chronic Obstructive Lung Disease 2017 Report: GOLD Executive Summary. Arch Bronconeumol. 2017;53(3):128-149.

49. Barrecheguren M, Esquinas C, Miravitlles M. The asthma-chronic obstructive pulmonary disease overlap syndrome (ACOS): opportunities and challenges. Curr Opin Pulm Med. 2015;21(1):74-79.

50. Santos S, Marin A, Serra-Batlles J, et al. Treatment of patients with COPD and recurrent exacerbations: the role of infection and inflammation. Int J Chron Obstruct Pulmon Dis. 2016;11:515-525.

51. Shaw JG, Vaughan A, Dent AG, et al. Biomarkers of progression of chronic obstructive pulmonary disease (COPD). J Thorac Dis. 2014;6(11): 1532-1547.

52. Tunney MM, Einarsson GG, Wei L, et al. Lung microbiota and bacterial abundance in patients with bronchiectasis when clinically stable and during exacerbation. Am J Respir Crit Care Med. 2013;187(10): $1118-1126$. 
International Journal of COPD

\section{Publish your work in this journal}

The International Journal of COPD is an international, peer-reviewed journal of therapeutics and pharmacology focusing on concise rapid reporting of clinical studies and reviews in COPD. Special focus is given to the pathophysiological processes underlying the disease, intervention programs, patient focused education, and self management protocols.

This journal is indexed on PubMed Central, MedLine and CAS. The manuscript management system is completely online and includes a very quick and fair peer-review system, which is all easy to use. Visit http://www.dovepress.com/testimonials.php to read real quotes from published authors 